\title{
Associação de medicamentos homeopáticos promove diminuição da parasitemia e melhora clínica em camundongos infectados por Trypanosoma cruzi
}

\author{
Gislaine Janaina Falkowski-Temporini ${ }^{\mathrm{a},{ }^{*}}$, Carina Ribeiro Lopes ${ }^{\mathrm{a}}$, Paula Fernanda \\ Massini $^{\mathrm{a}}$, Camila Fernanda Brustolin ${ }^{\mathrm{a}}$, Fabiana Nabarro Ferraz ${ }^{\mathrm{a}}$, Patricia Flora Sandri ${ }^{\mathrm{b}}$, \\ Denise Lessa Aleixo ${ }^{c}$, Silvana Marques de Araújo ${ }^{\mathrm{d}}$. \\ âPós-graduação em Ciências das Saúde, Universidade Estadual de Maringá, Maringá, PR, Brasil. \\ bós-graduação em Biociências e Fisiopatologia, Universidade Estadual de Maringá, Maringá, PR, Brasil. \\ ${ }^{\mathrm{c}}$ Centro Universitário de Maringá - UNICESUMAR, Maringá, PR, Brasil. \\ ${ }^{\mathrm{d}}$ Departamento de Ciências da Saúde, Universidade Estadual de Maringá, Maringá, PR, Brasil.
}

\section{Histórico do Artigo \\ Recebido em: \\ 31/10/2017 \\ Aceito em: \\ $18 / 03 / 2018$}

\section{Palavras-chave:}

Trypanosoma cruzi; homeopatia; organoterápico; medicamento constitucional.

Key words: Trypanosoma cruzi; homeopathy; organotherapic; constitutional medicine.

\begin{abstract}
RESUMO
Medicamentos homeopáticos constitucionais são utilizados para desencadear reações no organismo, diminuindo a suscetibilidade mórbida, enquanto que medicamentos organoterápicos têm como princípio a identidade biológica, restabelecendo a função do órgão através do homólogo sadio. Objetivo: avaliar o efeito da associação do medicamento constitucional Lycopodium clavatum com organoterápicos de baço e coração de camundongos sadios, sobre aspectos parasitológicos e clínicos da infecção murina por Trypanosoma cruzi. Camundongos infectados (1400 tripomastigotas-cepa-Y T. cruzi) foram divididos conforme tratamento: GLB (L. clavatum e organoterápico de baço 13c) n=10; GLC (L. clavatum e organoterápico de coração $13 \mathrm{c}$ ) $n=10$; GLBC (L. clavatum, organoterápicos de baço e coração 13c) n=11; GCI (solução hidroalcoólica $7 \%$, veículo de preparação dos medicamentos), $\mathrm{n}=11$. A parasitemia total foi significativamente menor em GLB e GLBC em relação ao GCI ( $p<0,05)$. O GLBC apresentou pico de parasitos significativamente menores que todos os grupos avaliados e o maior período pré-patente em relação ao GCI $(p<0,05)$. O GLBC e GLB tiveram maior temperatura e peso corporal em relação ao GCI ao longo da infecção $(\mathrm{p}<0,05)$. O aumento do consumo de ração foi significativamente maior somente no GLBC em relação ao GCI no fim do período patente $(p<0,05)$, demonstrando estado mais saudável em relação aos demais grupos. Os resultados sugerem que associações do medicamento constitucional ao organoterápico de baço mais coração melhoram a morbidade, com melhora clínica e redução parasitária em camundongos infectados pela cepa Y de T. cruzi que é altamente patogênica. Os resultados encorajam o uso de medicamentos homeopáticos no tratamento da doença de Chagas.
\end{abstract}

Association of homeopathic medicines promotes decreased parasitaemia and clinical improvement in mice infected with Trypanosoma cruzi

\section{ABSTRACT}

Constitutional homeophatic medicines are used to trigger reactions in the body, reducing the susceptibility morbid, while organotherapics medicines have as a principle biological identity restoring function through the homologous healthy. Aim: evaluate the effect of the constitutional medicine Lycopodium clavatum association with organotherapics of the spleen and heart of healthy mice on parasitological and clinical aspects of murine infection by Trypanosoma cruzi. Infected mices (1400 tripomastigotes-strain-Y T. cruzi) was formed according to treatment: GLB (L. clavatum and spleen's organotherapic 13c) $\mathrm{n}=10$; GLC (L. clavatum and heart's organotherapic 13c) $\mathrm{n}=10 ; \operatorname{GLBC}($ L. clavatum, spleen and heart's organotherapics $13 \mathrm{c}) \mathrm{n}=11 ; \mathrm{GCI}(7 \%$ hydroalcoholic solution, vehicle of preparation of the medicines), $n=11$. The total parasitaemia was significantly lower in GLBC and GLC than GCI $(p<0,05)$. GLBC presented smaller parasitic peak than all the groups and highest pre-patent period in relation to the GCI ( $<<0,05)$. GLBC and GLB had higher temperature and body weight in relation to GCI throughout the infection $(\mathrm{p}<0,05)$. The increase in feed intake was significantly higher only in GLBC compared to GCI at the end of the patent period $(\mathrm{p}<0,05)$, showing a healthier state than the other groups. The results suggest that the associations of constitutional medicine to organotherapic made from heart and spleen, decrease the morbidity of the infection, with clinical improvement by reducing parasitism in mice infected with the $\mathrm{Y}$ strain of $T$. cruzi, which is highly pathogenic. The results encourage the use of homeopathic medicines in the treatment of Chagas' disease.

\footnotetext{
*Autor Correspondente: gisajanaina@hotmail.com (G. J. Falkowski-Temporini)
} 


\section{Introdução}

A doença de Chagas representa um grave problema de saúde pública na América Latina, com estimativa de 10.000 óbitos/anos, segundo a Organização Mundial da Saúde (OMS), representando um gasto de US\$ 7 bilhões/ano (1). O Benznidazol, medicamento disponível para tratamento etiológico da doença, apresenta diversos efeitos adversos e baixa adesão pelos pacientes, havendo a necessidade de se desenvolver medicamentos mais eficientes e com menos efeitos colaterais. No Brasil, pesquisas envolvendo a homeopatia são incentivadas considerando a aprovação da Portaria do Ministério da Saúde n.971/2006, regulamentando a abordagem da Política Nacional de Práticas Integrativas e Complementas (PNPIC) no Sistema único de Saúde (SUS).

A homeopatia tem sido pesquisada como forma integrativa e complementar de tratamento de diversas doenças, via estímulos de resposta biológica. Medicamentos homeopáticos constitucionais são utilizados para desencadear reações no organismo, diminuindo a suscetibilidade mórbida, enquanto que os medicamentos organoterápicos (preparados a partir de órgãos de animal sadio) têm como princípio a identidade biológica, restabelecendo a função do órgão doente através do homólogo sadio $(2,3)$.

A literatura é carente de informação científica que aborde os efeitos desses medicamentos. Nesse contexto, o objetivo deste trabalho foi avaliar o efeito da associação do medicamento constitucional Lycopodium clavatum com organoterápicos de baço e coração de camundongos sadios, sobre aspectos parasitológicos e clínicos da infecção murina por Trypanosoma cruzi.

\section{Materiais e métodos}

\section{1. Ética}

O laboratório onde foi realizada a pesquisa é credenciado pelo Conselho Nacional de Controle de Experimentação Animal (CEUA/UEM) e adere aos princípios enunciados na $8^{\circ}$ edição do Guide for the Care and Use of Laboratory Animals, National Research Council, 2011. O Estudo foi aprovado pelo Comitê de Ética em Experimentação Animal (CEEA-UEM), protocolo 54/2011.

\subsection{Delineamento experimental}

O estudo foi realizado em ensaio cego, controlado e randomizado por sorteio. Foram utilizados 42 camundongos da espécie Mus musculus, linhagem Swiss, machos de 8 semanas de idade, divididos em quatro grupo de animais, provenientes do Biotério Central/UEM, mantidos em biotério setorial de experimentação (laboratório de parasitologia) por uma semana antes do início da pesquisa para ambientalização, sob temperatura, umidade e iluminação controladas com água e ração ad libitum.

\subsection{Grupos experimentais}

Os grupos foram divididos de forma randomizada, de modo que o peso médio para cada grupo não tivesse diferença estatística significativa entre si. Os animais foram infectados por via intraperitoneal com 1.400 tripomastigotas sanguíneos da cepa Y de $T$. cruzi. Foram constituídos os grupos: GLB - tratado com L. clavatum e organoterápico de baço $13 \mathrm{c}(\mathrm{n}=10)$, GLC - tratado com L. clavatum e organoterápico de coração $13 \mathrm{c}$ $(\mathrm{n}=10)$, GLBC - tratado com L. clavatum, organoterápicos de baço e coração $13 \mathrm{c}$ 
$(\mathrm{n}=11)$ e GCI Grupo tratado com veículo de preparação do medicamento (solução hidroalcoólica $7 \%)(\mathrm{n}=11)$.

\subsection{Seleção e preparo do medicamento constitucional}

O medicamento foi selecionado a partir da repertorização de animais não infectados, de acordo com Zandvoort (4) e Matéria Médica Homeopática (5), observando as características idiossincráticas do grupo, considerando comportamento, socialização e fisiologia. A observação dos animais foi realizada por três homeopatas, durante 30 minutos em ambiente silencioso, das $19 \mathrm{~h}$ às $19 \mathrm{~h} 30 \mathrm{~min}$, considerando o período noturno de atividade para roedores. As características foram inseridas no Software Lince Expert System (Albuquerque, EUA), chegando ao consenso de três medicamentos (Kalium causticum, Conium maculatum e Lycopodium clavatum), sendo que o Lycopodium clavatum cobriu o maior número de características da repertorização, assim foi associado ao organoterápico $(6,7)$. Esse medicamento foi escolhido, considerando a Lei de Similitude de acordo com a prática clínica convencional descrita por Hahnemann (8).

O Lycopodium clavatum (Deutsche Homöopathie-Union, Alemanha) foi preparado a partir da tintura mãe diluída com álcool de cereais (Agro-Industrial Tarumã Ltda, São Pedro do Turvo, Brasil) a 70\% até a dinamização 12c (9). A dinamização de uso dos medicamentos (13c) foi preparada em álcool 7\%, utilizando dinamizador mecânico (Dinamizador AUTIC®).

\subsection{Seleção e preparo dos medicamentos organoterápicos}

As características reticulotrópicas da cepa $\mathrm{Y}$ de Trypanosoma cruzi foram consideradas para o tropismo no baço, fígado e coração (10) e selecionou-se o medicamento preparado a partir de fragmentos frescos de coração e baço sadios de camundongos Swiss de 8 semanas.

Os organoterápicos foram preparados a partir do macerado de seus respectivos órgãos e diluídos com álcool de cereais (Agro-Industrial Tarumã Ltda, São Pedro do Turvo, Brasil) a $70 \%$ até a dinamização 12c (9). A dinamização 13c de uso dos medicamentos foi preparada em álcool $7 \%$ (9).

\subsection{Controle de infecção}

Como controle, foi utilizado o álcool 7\%, veículo de preparação dos medicamentos, de acordo com a Farmacopeia Homeopática Brasileira (9).

\subsection{Esquema de tratamento}

Todos os grupos receberam o tratamento com o L. clavatum 2 dias antes da infecção e 2, 4 e 6 dias após a inoculação. Segundo prática clínica, o L. clavatum foi associado ao organoterápico 2 dias após a inoculação. Os medicamentos e seu veículo foram sucussionados, oferecidos diluídos em água $(1 \mathrm{~mL} / 100 \mathrm{~mL})$ ad libitum, em bebedouro âmbar, por toda a noite, durante 16 horas (11).

Os medicamentos foram preparados na dinamização $13 \mathrm{c}$ (diluição $1: 10^{26}$ ), segundo prática clínica homeopática e entendendo a infecção experimental murina por $T$. cruzi como uma patologia aguda e considerando os camundongos Swiss como animais de pequeno porte $(6,12)$. 


\subsection{Parâmetros avaliados}

\subsubsection{Parâmetros Parasitológicos}

A parasitemia foi avaliada segundo técnica de Brener (13), com contagem diária de parasitos a partir do primeiro dia de infecção, até resultado negativo por três exames consecutivos ou até a morte do animal. A curva de parasitemia foi traçada, utilizando a parasitemia média para cada grupo. A partir da curva de parasitemia, foram obtidos o período pré-patente (PPP - tempo entre a inoculação e o primeiro dia de positividade no exame de sangue a fresco), período patente ( $\mathrm{PP}$ - tempo médio, em que o parasito foi detectado no sangue), pico máximo de parasitemia (PMax - maior parasitemia média observada) e parasitemia total (PT - média da soma da parasitemia de cada camundongo ao longo do experimento).

\subsubsection{Parâmetros clínicos}

Os animais foram divididos em quatro grupos, mantidos em gaiolas e avaliados durante cinco dias antes da infecção, no dia da infecção e 27 dias consecutivos após a infecção em horário fixo (14). Os seguintes parâmetros foram avaliados: Peso expresso em grama $(\mathrm{g})$, avaliado individualmente em balança digital BEL engineering ${ }^{\circledR}$ - Class Mark II 500g; Temperatura - expressa em grau centigrado (o C), medida individualmente na região anterior da coxa traseira esquerda (menor quantidade de pelos), utilizando termômetro infravermelho digital Icel (modelo TD-920.0387); Consumos de água e ração - expressos em mililitro (mL) e grama (g), respectivamente. Avaliados coletivamente, considerando o valor inicial oferecido ao grupo subtraído do valor medido após um dia de consumo. $\mathrm{O}$ valor obtido foi dividido pelo número de animais para estimar valores individuais; Quantidade de excretas expressa em grama, foi obtida pela pesagem da cama das gaiolas antes do uso e subtraída do valor da pesagem após um dia de uso. Foram consideradas fezes e urina conjuntamente; Análise qualitativa: foi analisada a letargia do animal, utilizando categorias numéricas definidas como: zero para presença e 1 (um) para ausência, considerando que a cepa $\mathrm{Y}$ de Trypanosoma cruzi provoca a letargia dos animais e a possibilidade de ação do medicamento sob esse aspecto.

\subsection{Análise de sobrevida}

Foi avaliada até 85 dias após a infecção e calculado o tempo médio de vida para cada grupo, considerando GLB (n=7), GLC ( $n=7)$, GLBC (n=8), GCI (n=8).

\subsection{Análise estatística}

A análise estatística foi realizada pela comparação dos diferentes parâmetros entre os grupos tratados e controle, utilizando teste " $t$ " de Student (dados paramétricos) e o teste de Mann-Whitney (dados não paramétricos), utilizando o Software Statistic 8.0. A análise de sobrevida foi realizada com o teste Logrank - programa R.2.10.0. O nível de significância adotado nos testes foi de 5\%. 


\section{Resultados}

\subsection{Parâmetros Parasitológicos}

A parasitemia total foi significativamente menor em GLBC $\left(7,5 \pm 2,7 \times 10^{6}\right)$ e GLB $\left(10,3 \pm 4,0 \times 10^{6}\right)$ comparada a GCI $\left(12 \pm 4 \times 10^{6}\right)(\mathrm{p}<0,05)$ (Figura 1, Tabela 1). Os três grupos que receberam medicamentos altamente diluídos apresentaram menores picos de parasitos no $8^{\circ}$ dia de infecção quando comparados ao GCI $(\mathrm{p}<0,05)$. GLBC apresentou o maior período pré-patente em relação a todos os grupos $(p<0,05)$. GLB apresentou maior período patente em relação ao GCI $(p<0,05)$. Embora não significante, os grupos GLB e GLBC demonstraram estimativas de tempo de sobrevivência de 11,8 dias e 10,6 dias, com $14 \%$ e $12 \%$ dos animais vivos respectivamente (Figura 2).

Tabela 1: Parâmetros parasitológicos em camundongos Swiss, machos, oito semanas, infectados com 1400 tripomastigotas sanguíneos de T. cruzi, cepa Y, tratados com solução hidroalcoólica a 7\% (GCI), associação de medicamento constitucional Lycopodium clavatum $13 \mathrm{c}$ com o organoterápicos de baço (GLB), associação de medicamento constitucional Lycopodium clavatum 13c com organoterápico de coração (GLC) e associação de medicamento constitucional Lycopodium clavatum 13c com organoterápico de coração e baço (GLBC).

\begin{tabular}{llllll}
\hline Grupos & PPP (dias) & PP (dias) & PMax $\left(\times 10^{6}\right)$ & $\mathrm{P}_{\text {total }}\left(\times 10^{6}\right)$ & $\begin{array}{l}\text { Estimativa de } \\
\text { sobrevida (dias) }\end{array}$ \\
\hline GCI & $4,1 \pm 0,3$ & $10,8 \pm 4,6$ & $7,6 \pm 2,5$ & $12 \pm 4$ & 25 \\
GLC & $4,1 \pm 0,3$ & $11,3 \pm 5,2$ & $6,0 \pm 1,8^{*}$ & $12 \pm 4,8$ & 25 \\
GLB & $4,1 \pm 0,3$ & $13 \pm 5^{*}$ & $5,4 \pm 2,2^{*}$ & $10,3 \pm 4,0^{*}$ & 85 \\
GLBC & $4,7 \pm 0,9^{*}$ & $10,2 \pm 4,4$ & $4,2 \pm 1,9^{*}$ & $7,5 \pm 2,7^{*}$ & 85 \\
\hline
\end{tabular}

*Diferenças significativas em relação ao GCI $(\mathrm{p}<0,05)$; Dados apresentados com média mais ou menos $o$ desvio padrão. PPP (período pré-patente), PP (período patente), PMax (pico máximo de parasitos no $8^{\circ}$ dia de infecção), Ptotal (parasitemia total).

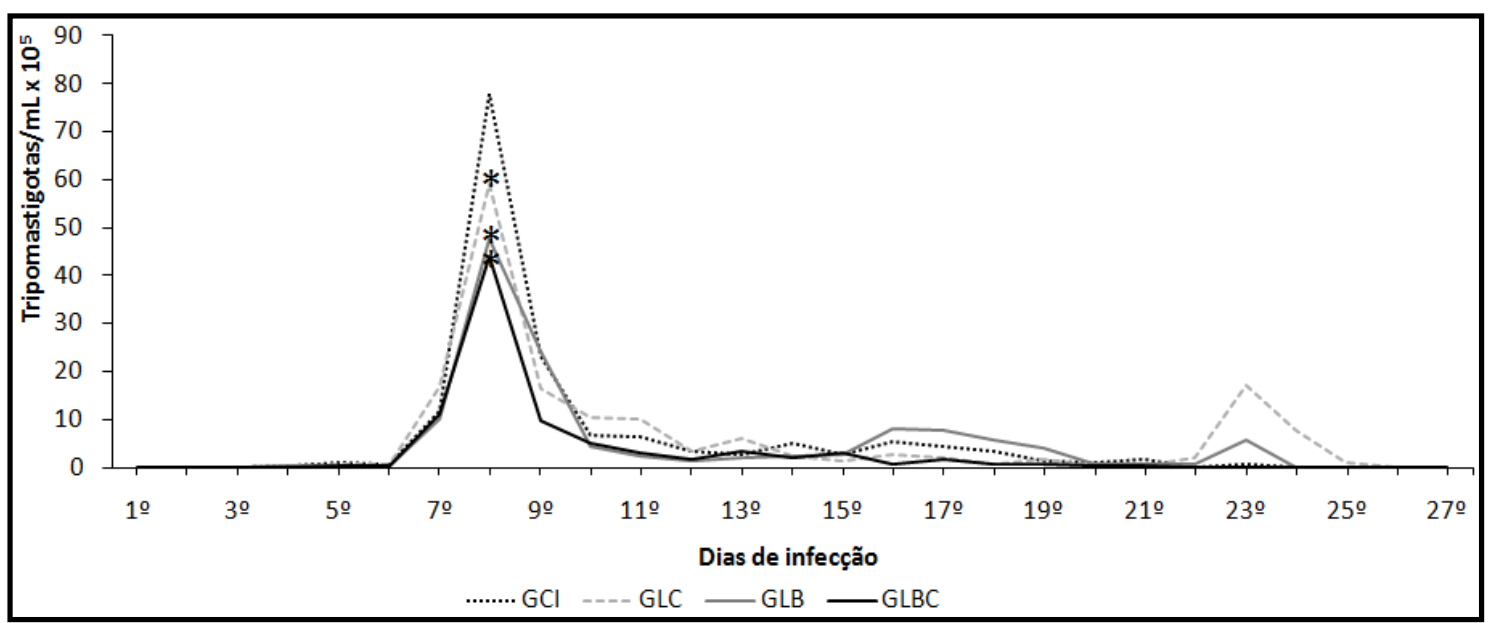

Figura 1: Curva de parasitemia média, a partir do $1^{\circ}$ dia de infecção ao $27^{\circ}$ dia de infecção de camundongos "Swiss" machos, 8 semanas de vida, submetidos ao inóculo com 1400 formas tripomastigotas sanguíneos da cepa Y do T. cruzi, tratados com solução hidroalcoólica a $7^{\circ}$ GL (GCI); Lycopodium clavatum e organoterápico de coração 13c (GLC); Lycopodium clavatum e organoterápico de baço 13c (GLB); Lycopodium clavatum, organoterápicos de baço e coração 13c (GLBC). * p<0,05. 


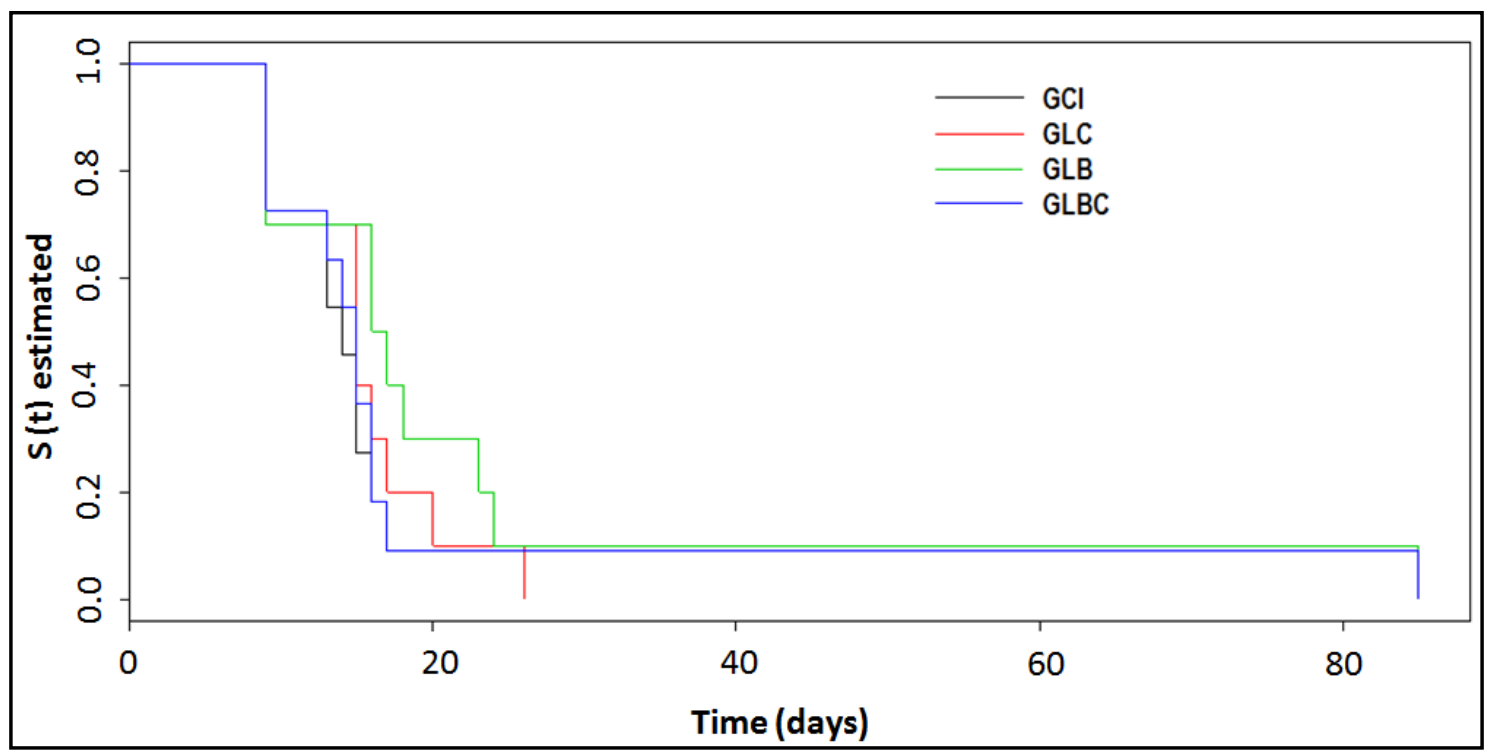

Figura 2: Análise de sobrevida de camundongos submetidos ao inóculo com 1400 formas tripomastigotas sanguíneos da cepa Y do T. cruzi, tratados com solução hidroalcoólica a $7^{\circ}$ GL (GCI); Lycopodium clavatum e organoterápico de coração 13c (GLC); Lycopodium clavatum e organoterápico de baço 13c (GLB); Lycopodium clavatum, organoterápicos de baço e coração 13c (GLBC).

\subsection{Parâmetros Clínicos}

A tabela 2 resume os dados dos parâmetros clínicos obtidos. O grupo GLBC apresentou melhora na condição clínica, expressa pelo aumento da temperatura, maior quantidade de ração consumida e ganho de peso corporal em relação ao GCI ( $p<0,05)$.

Os grupos GLB e GLBC apresentaram temperaturas corpóreas mais elevadas do que GCI, desde o início da infecção até o $19^{\circ}$ dia após a inoculação $(\mathrm{p}<0,05)$, enquanto que GLC apresentou aumento de temperatura em relação ao GCI do início da infecção até o $13^{\circ}$ dia após a inoculação $(\mathrm{p}<0,05)$.

O ganho de peso foi observado nos grupos GLBC e GLB em comparação ao GCI no final do período patente, correspondente ao 20-25 dias de infecção $(p<0,05)$. Em contrapartida, o GLC apresentou redução desse parâmetro nesse mesmo período em relação ao GCI $(\mathrm{p}<0,05)$.

Durante o período do início da infecção até o $8^{\circ}$ dia de infecção, correspondente ao maior pico de parasitos circulantes, houve aumento do consumo de água em todos os grupos tratados com os medicamentos altamente diluídos em relação ao GCI ( $p<0,05)$.

O maior consumo de ração foi observado no grupo GLBC em relação ao GCI no final do período patente (20-25 dias de infecção) e a maior quantidade de excretas foram observadas nos grupos GLB e GLBC do $9^{\circ}$ ao $13^{\circ}$ dias de infecção em relação ao GCI $(\mathrm{p}<0,05)$.

No parâmetro qualitativo, a ausência de letargia dos animais apenas pôde ser observado no grupo GLBC em relação ao GCI $(\mathrm{p}<0,05)$. 
Tabela 2: Média para parâmetros clínicos em camundongos Swiss, machos, oito semanas, infectados com 1400 tripomastigotas sanguíneos de T. cruzi, cepa Y, tratados com solução hidroalcoólica a 7\% (GCI), associação de medicamento constitucional Lycopodium clavatum 13 c com o organoterápico de baço (GLB), associação de medicamento constitucional Lycopodium clavatum 13c com organoterápico de coração (GLC) e associação de medicamento constitucional Lycopodium clavatum 13c com organoterápico de coração e baço (GLBC).

\begin{tabular}{lllllll}
\hline Grupos & $\begin{array}{c}\text { Dia de } \\
\text { Infecção }\end{array}$ & $\begin{array}{c}\text { Temperatura } \\
\text { corporal }\left({ }^{\circ} \mathbf{C}\right)\end{array}$ & $\begin{array}{c}\text { Peso } \\
(\mathbf{g})\end{array}$ & Agua $(\mathbf{m L})$ & $\begin{array}{c}\text { Ração } \\
(\mathbf{g})\end{array}$ & $\begin{array}{c}\text { Excretas } \\
\text { (g) }\end{array}$ \\
\hline GCI & $0-8$ & $32,7 \pm 1,2$ & $43,5 \pm 3,8$ & $10 \pm 1,3$ & $8,2 \pm 1,2$ & $8,9 \pm 3,5$ \\
& $9-13$ & $31,6 \pm 0,9$ & $41,7 \pm 3,7$ & $4,9 \pm 1,5$ & $2,2 \pm 1$ & $3,3 \pm 0,5$ \\
& $14-19$ & $28,4 \pm 2,1$ & $37,2 \pm 4$ & $4,9 \pm 4,3$ & $2,7 \pm 1,9$ & $5,7 \pm 3$ \\
& $20-25$ & $29,6 \pm 1,8$ & $34,5 \pm 1,7$ & $15 \pm 0$ & $3,9 \pm 2,1$ & $11,7 \pm 2,8$ \\
GLC & $0-8$ & $33,4 \pm 1,5^{*}$ & $42,7 \pm 3,2$ & $10,7 \pm 1,4^{*}$ & $8,8 \pm 1,2^{*}$ & $9,5 \pm 4$ \\
& $9-13$ & $32,5 \pm 0,7^{*}$ & $44 \pm 3,5$ & $5,2 \pm 1,8$ & $2,9 \pm 1,4$ & $3,8 \pm 0,4$ \\
& $14-19$ & $28,4 \pm 1,5$ & $38,4 \pm 4$ & $2,9 \pm 2$ & $2,1 \pm 0,9$ & $3,8 \pm 2,5$ \\
& $20-25$ & $28,5 \pm 1,8$ & $31,1 \pm 2,8^{*}$ & $10 \pm 44,4$ & $4,3 \pm 2,1$ & $9,7 \pm 3,7$ \\
GLB & $0-8$ & $33,6 \pm 1,2^{*}$ & $43,6 \pm 3,2$ & $10,6 \pm 1^{*}$ & $8,6 \pm 1,3$ & $9,7 \pm 3,7$ \\
& $9-13$ & $33,2 \pm 0,9^{*}$ & $45,8 \pm 4,4^{*}$ & $5,9 \pm 2,4$ & $3,6 \pm 1,6^{*}$ & $4,6 \pm 0,2^{*}$ \\
& $14-19$ & $29,8 \pm 1,8^{*}$ & $41,1 \pm 4,2^{*}$ & $2,8 \pm 1,7$ & $2,1 \pm 1,2$ & $3,6 \pm 0,8$ \\
& $20-25$ & $30,3 \pm 1,7$ & $38,5 \pm 2,1^{*}$ & $7,2 \pm 0,8$ & $4,2 \pm 0,7$ & $4,7 \pm 0,4$ \\
GLBC & $0-8$ & $33,8 \pm 1^{*}$ & $42,6 \pm 3,5$ & $10,4 \pm 1,2^{*}$ & $7,8 \pm 0,7 *$ & $8,7 \pm 3,3$ \\
& $9-13$ & $32,7 \pm 1,2^{*}$ & $42,8 \pm 3,5$ & $6 \pm 2,7$ & $3,2 \pm 1,6^{*}$ & $3,8 \pm 1,3^{*}$ \\
& $14-19$ & $30,2 \pm 1,3^{*}$ & $38 \pm 1,2$ & $5 \pm 4,4$ & $2,4 \pm 2,3$ & $5,1 \pm 2,7$ \\
& $20-25$ & $28,4 \pm 2,8$ & $37,4 \pm 1,2^{*}$ & $11,2 \pm 2,3$ & $7,5 \pm 2,6^{*}$ & $10,5 \pm 3,9$ \\
\hline
\end{tabular}

*Diferenças significativas em relação ao GCI $(\mathrm{p}<0,05)$ em mesmo período avaliado.

\section{Discussão}

As reduções de parasitemia em todos os grupos tratados com medicamentos homeopáticos demonstram ação sobre o curso da infecção por T. cruzi. Independente do mecanismo, ao promoverem a redução da parasitemia, os medicamentos altamente diluídos proporcionam menores oportunidades de inflamação, um dos fenômenos centrais da patogenia da infecção por T. cruzi $(6,15)$.

O benefício do bioterápico de baço e coração associado ao medicamento constitucional (grupo GLBC) pode ser verificado através do maior PPP observado $(\mathrm{p}<0,05)$, da menor parasitemia com menor pico de parasitos em relação a todos os grupos avaliados (Tabela 1). A tendência a aumentar o PPP e não aumentar o PP foi demonstrada em trabalhos anteriores, significando benefício para animais tratados, indicando o controle da infecção $(11,16)$ em modelo animal extremamente sensível à cepa de T. cruzi utilizada (6).

A elevação da temperatura no período de 0 ao 19 dias de infecção em GLB e GLBC em comparação ao GCI revelou a ação benéfica desses medicamentos. Segundo a literatura, a temperatura corporal normal de camundongos Swiss está entre $36-37^{\circ} \mathrm{C}$. Em condição de hipotermia, verifica-se $33-34^{\circ} \mathrm{C}$ e de hipertermia $39-40^{\circ} \mathrm{C}$. Esses valores variam de acordo com idade e condições de experimentação (17). Diante de uma infecção que deixa os animais letárgicos com consequente diminuição da temperatura, o aumento térmico verificado em GLB e GLBC, em comparação ao GCI, reflete a ação medicamentosa contra a infecção para manutenção da homeostase fisiológica (18).

A melhor condição clínica apresentada por GLBC, expressa pelo aumento da temperatura, maior consumo de ração e ganho de peso corporal em relação ao GCI $(\mathrm{p}<0,05)$, representa maior homeostase em comparação aos demais grupos (18). Embora GLB tenha apresentado maior ganho de peso em relação ao GCI, a intervenção não foi suficiente para promover estado final mais saudável, como ocorreu em GLBC, que 
apresentou aumento significativo do consumo de ração em relação ao GCI $(p<0,05)$ no fim do período pré-patente.

A ingesta aumentada de alimento demonstra a melhor evolução clínica dos animais (19). A ausência de letargia apresentada em GLBC mostra a recuperação do estado letárgico produzido pela infecção, apesar de não ter sido demonstrada diferença significativa na sobrevida entre os grupos. Isso ocorre por se tratar de infecção com uma cepa que provoca mortalidade de todos os animais infectados nas condições experimentais deste trabalho (10).

A melhora clínica e a redução parasitária em GLBC se devem à soma de efeitos dos medicamentos utilizados. Pesquisas mostram que medicamentos altamente diluídos ativam ou inibem ações celulares específicas que se refletem na saúde do animal $(20,21,22)$. Em contrapartida, o organoterápico age restabelecendo a função do órgão através do homólogo sadio, servindo de modelo de informação para direção de reação do organismo.

O organoterápico independente do órgão utilizado e sem a associação não foi eficiente para manter o equilíbrio biofisiológico, estimulando fortemente o organismo e levando a uma resposta máxima do sistema biológico como observado em estudos anteriores (23). Isso pode ter ocorrido porque camundongos são naturalmente muito sensíveis à infecção por T. cruzi. Como alternativa para maximizar os resultados, a utilização de um modelo experimental mais resistente (Rattus norvegicus, por exemplo) manteria maior equilíbrio hospedeiro-parasito durante a infecção e permitiria evidenciar os efeitos benéficos do tratamento (24). Ainda poderia ser preparado organoterápico a partir de órgãos de espécie mais resistente ao $T$. cruzi.

O organoterápico, ao passar a informação de resposta de organismo sadio ao hospedeiro infectado, possivelmente modulou informações imunofisiológicas, que foram fornecidas de forma específica, nesse modelo experimental utilizado, reproduzindo a resposta de estado saudável ao hospedeiro através da homeostase, observado através de melhor morbidade e menor parasitemia. Esses e outros efeitos induzidos pelo organoterápico têm sido demonstrados por nosso grupo de pesquisa em publicações científicas $(7,24,25)$. No entanto, a espécie utilizada para a preparação dos organoterápicos é muito sensível $(10,25)$ e, com a utilização de modelo mais resistente, seria possível observar mais claramente o efeito equilibrado e benéfico do medicamento, refletido, também, na maior sobrevida de animais infectados por $T$. cruzi $(7,24)$.

Os resultados de melhora clínica e redução da parasitemia no tratamento da infecção murina com a associação de medicamentos organoterápicos de baço, coração e constitucional demonstram a ação no organismo para manter o equilíbrio biofisilógico, interferindo positivamente sobre o sistema biológico como um todo $(7,24,25)$, fato que não é conseguido pelo medicamento alopático benznidazol, que tem ação direta sobre o parasito e é responsável por efeitos colaterais importantes, como dermatopatia alérgica generalizada, neuropatia periférica e depressão da medula óssea, reações que levam, muitas vezes, à interrupção do tratamento (26). O medicamento homeopático não apresenta efeitos adversos e é de fácil adesão pelo paciente (4).

\section{Conclusão}

Diante dos resultados obtidos, concluímos que associação de medicamentos constitucionais com organoterápicos de órgãos afetados, em um esquema de tratamentono qual o constitucional é administrado previamente ao organoterápico, pode apresentar efeitos benéficos importantes e constituir em alternativa de tratamento interessante para diferentes agravos. Especificamente no caso da infecção aguda murina 
por T. cruzi, as associações do medicamento constitucional com organoterápico de baço mais coração e do medicamento constitucional com organoterápico de baço apresentaram efeitos benéficos, com redução da parasitemia e melhora do peso corporal quando comparado ao controle. No esquema de tratamento utilizado, os benefícios melhoraram os índices de sobrevivência, o que foi muito importante, uma vez que a literatura mostra que a infecção pela cepa Y de T. cruzi é altamente patogênica, levando à mortalidade total dos animais (10). Assim, esses resultados encorajam o uso de medicamentos homeopáticos no tratamento da doença de Chagas e na avaliação dessa estratégia de associação para outras patologias.

Conflito de interesses: A autora declara não haver conflito de interesses.

\section{Referências}

1. Lee BY, Bacon KM, Bottazzi ME, Hotez PJ. Global economic burden of Chagas disease: a computational simulation model. Lancet Infect Dis 2013; 13(4): 342-348.

2. Teixeira MZ. Protocolo de experimentação patogenética homeopática em humanos. São Paulo: Marcus Zulian Teixeira, 2013.

3. Castilhos LR, Souza JC, Pinto LF, Albuquerque FT, Filgueiras EP. Avaliação da Terapêutica Homeopática nas Ovariopatias Císticas de Bovinos Leiteiros. Homeopatia Brasileira 2003; 9 (1): 5-15.

4. Zandvoort R. The Complete Repertory. Institute for Research in Homeopathic Information and Symptomatology. In: Leidschendam AJ. The Netherlands; 1994-1996.

5. Allen TF. The Encyclopedia of pure material medica. Repr., Jain B. Publishers, New Delhi, 1982.

6. Lopes CR, Falkowski GJS, Brustolin CF, Massini PF, Ferreira EC, Moreira NM, et al. Highly diluted medication reduces tissue parasitism and inflammation in mice infected by Trypanosoma cruzi. Homeopathy 2016; 105(2): 186-193.

7. Falkowski-Temporini GJ, Lopes CR, Massini PF, Brustolin CF, Sandri PF, Ferreira EC, Aleixo DL, Pala NR, de Araújo SM. Predominance of Th1 response, increase of megakaryocytes and Kupffer cells are related to survival in Trypanosoma cruzi infected mice treated with Lycopodium clavatum, Cytokine 2016; 88:57-61.

8. Hahnemann CFS. Organon der Heilkunst. In: 6th ed., Heidelberg: Haug, 1989.

9. Brasil. Farmacopéia Homeopática Brasileira. ANVISA. $3^{\mathrm{a}}$ ed. Agência Nacional de Vigilância Sanitária, Brasília DF; 2011.

10. Silva LHP, Nussenzweig V. Sobre uma cepa de Trypanosoma cruzi altamente virulenta para o camundongo branco. Folia Clínica Biol. São Paulo 1953; 20: 191-201.

11. Aleixo DL, Ferraz FN, Ferreira EC, Lana M, Gomes ML, Filho BAA, Araújo SM. Highly diluted medication reduces parasitemia and improves experimental infection evolution by Trypanosoma cruzi. BMC Research Notes 2012; 5(352): 1-8.

12. Bellavite P, Signorini A, Marzotto M, Moratti E, Bonafini C, Olioso D. Cell sensitivity, non-linearity and inverse effects. Homeopathy 2015; 104: 139-160.

13. BRENER Z. Therapeutic activity and criterion of cure on mice experimentally infected with Trypanosoma cruzi. Rev Inst Med Trop 1962; 4: 389-396.

14. Falkowski, GJS, Sandri PF, Tiyo R, Aleixo DL, Araújo SM. Parameters for evaluation of clinical Trial in mice infected by Trypanosoma cruzi. Arq Bras Med Vet Zootec 2012; 64: 1539-1546.

15. Bellavite P, Andrioli G, Lusslgnoli S, Slgnorini A, Ortolani R, Conforti A. A scientific reappraisal of the 'principle of similarity'. Medical Hypotheses 1997; 49: 203-212.

16. Ferraz FN, da Veiga FK, Aleixo DL, Ciupa L, de Abreu Filho BA, da Silva SS et al. Biotherapies of rabbit serum modulate the immune response and decrease parasite load in mice infected with Trypanosoma cruzi, J. Appl. Biomed 2016; 14(3): 187-197.

17. Fox JG, Barthold SW, Davisson MT. The Mouse in Biomedical Research: Diseases. 2 ed. San Diego: Elsevier, 2007.

18. Aleixo DL, Benvenutti MJ, Lera KRJL, Ciupa L, Ferraz FN, de Araújo SM. The Association of 
Ponderal Benznidazole with its Ultra-high Diluted Formula Reduces the Toxic Effects and Allows Increasing of Dose in Dose-dependent Protocol in Mice Infected with Trypanosoma cruzi. Int. J. High Dil. Res. 2015; 14(3): 10-19.

19. Gaskill BN, Gordon CJ, Pajor EA, Lucas JR, Davis JK, Garner JP. Impact of nesting material on mouse body temperature and physiology. Physiol Behav. 2013; 110-111: 87-95.

20. Bell IR, Koithan M. A model for homeopathic remedy effects: low dose nanoparticles, allostatic cross-adaptation, and time dependent sensitization in a complex adaptive system. BMC Complement Altern Med 2012; 12: 191.

21. Kayser O, Kiderlen AF, Croft SL. Natural products as antiparasitic drugs. Parasitol Res. 2003; 90 Suppl 2:S55-62.

22. Samadder A, Das S, Das J, Paul A, Boujedaini N, Khuda-Bukhsh AR. The potentized homeopathic drug, Lycopodium clavatum (5C and 15C) has anti-cancer effect on hela cells in vitro. J Acupunct Meridian Stud 2013; 6: 180-187.

23. Oberbaum M, Frass M, Cornelius Gropp. Unequal brothers: are homeopathy and hormesis linked? Homeopathy 2015; 104(2): 97-100.

24. Ferraz, FN; Veiga, FK; Aleixo, DL; Spack, M; Araújo SM. Different treatment schemes and dynamizations of Trypanosoma cruzi biotherapies: what information do they transfer to the organism in infected mice? Homeopathy 2016; (4): 305-310.

25. Ferraz FN, da Veiga FK, Aleixo DL, Silva SS, Conchon-Costa I, Pavanelli WR, et al. Modulation of IFN-gama, IL-4 and IL-17 Cytokines is Related to Parasitemia Control in Mice Infected by Trypanosoma cruzi and Treated with Biotherapy. J Biol Sci 2015; 15: 251-259.

26. Oliveira MF, Nagao-Dias AT, Pontes VMO, Júnior ASS, Coelho HLL, Coelho ICB. Tratamento etiológico da doença de chagas no Brasil. Revista de Patologia Tropical, 2008; 37(3) 209-228. 